\title{
Study on dielectric property of BST of gradient thick films
}

\author{
Maoyan Fan \\ School of Information Technology and Engineering \\ Yuxi Normal University \\ Yuxi, China \\ e-mail:fanmaoyan@vip.sina.com
}

\author{
Lifang Zhang \\ School of Information Technology and Engineering \\ Yuxi Normal University \\ Yuxi, China \\ e-mail:ff@yxnu.net
}

\begin{abstract}
The multilayer BST thick film with composition gradient is becoming the important alternative material for the infrared detector and microwave modulator due to its good comprehensive dielectric properties such as moderate dielectric constant and high dielectric-temperature coefficient, etc. The Mn-doped BST thick film with six different layers of composition gradients is fabricated in the $\mathrm{Pt} / \mathrm{Ti} / \mathrm{SiO}_{2} / \mathrm{Si}$ silicon chip by improved sol-gel method. The thick film is about $5 \mu \mathrm{m}$ thick. Then the micro structure and dielectric property of the gradient thick film is studied. The XRD analysis shows that the thick film with complete perovskite structure can be obtained when the heat treatment temperature reaches $750^{\circ} \mathrm{C}$. The SEM microscope demonstrates that the surface grains have uniform size with dense arrangement and good density, and the dielectric peak temperature zone of the gradient BST thick film covers the normal temperature with dielectric coefficient 920 and dielectric loss approximately $1.8 \times 10^{-2}$.
\end{abstract}

Keywords- sol-gel; Mn doping; thick film; composition gradient; dielectric property

\section{INTRODUCTION}

As a typical composite with perovskite structure, $\left(\mathrm{Ba}_{1-}\right.$ ${ }_{x} \mathrm{Sr}_{\mathrm{x}} \mathrm{TiO}_{3}$ not only performs high dielectric constant, low dielectric loss and good $\mathrm{SrTiO}_{3}$ physicochemical stability like $\mathrm{BaTiO} 3$ but also shows perfect ferroelectric, piezoelectric and pyroelectric properties. Comparing with other methods to fabricate BST thick film, the sol-gel method has some special advantages: (1) good uniformity and multicomponent production which can assure the correct stoichiometry and single crystal structure; (2) easy micro doping to improve the thick film performance; (3) low heat treatment temperature; (4) cheap fabrication of large thick film with high purity which is easy to industrialize. The BST thick film especially performs modulated dielectric constant, low dielectric loss and leakage current density and other excellent properties. Thus the BST thick film is considered as the primary material for the uncooled infrared detector.

The BST thick film, though with high dielectric constant and dielectric-temperature coefficient, has also the disadvantages such as high dielectric loss and thin dielectric peak. It is hard to satisfy application due to small dielectric peak dispersion, though the dielectric loss can be improved by doping, fabrication technique and crystallization process. The dielectric loss of the monolayer BST thick film fabricated by the component doping such as non-ferroelectric compound doping,rare earth and other doping can be decreased, but its dielectric-temperature characteristics is also decreased obviously. Thus, more attention is paid to the component (including the doping) gradient layer and multilayer[1-3].

The concept of function gradient material (FGM) was firstly provided [8] by several material scientists in Japan in around 1984. The American men Im and other persons developed the monolayer and multilayer BST thick film with $[(\mathrm{Ba}+\mathrm{Sr}) / \mathrm{Ti}]$ range from 0.73 to 0.98 by the magnetron sputtering method. The capacitor with multilayer BST thick film performs a more excellent dielectric property than that with monolayer BST thick film. The dielectric properties of BST thick film with different $(\mathrm{Ba} / \mathrm{Sr})$ gradient were researched in detail by the Hong Kong Polytechnic University [4,5]. Some similar study was also conducted by Zhai and other persons in the City University of Hong Kong [6], who fabricated BST thick film with different $(\mathrm{Ba} / \mathrm{Sr})$ gradient on the $\mathrm{LaNiO}_{3} / \mathrm{Pt} / \mathrm{Ti} / \mathrm{SiO}_{2} / \mathrm{Si}$ silicon chip by the solgel method and then obtained the $37 \%$ tuning rate under 1 $\mathrm{MHz}$ and $300 \times 10^{3} \mathrm{~V} / \mathrm{cm}$ electrical field as well as small dielectric-temperature coefficient. The Korean men Lee and other persons fabricated the BST thick film with gradual decrease of up and bottom ( $\mathrm{Ba} / \mathrm{Sr}$ ) gradients [7]. The results showed that the different directions of component gradient can result in different microstructures of gradient layers, which may cause difference in microwave properties. Cao and other persons from Suzhou University made a study on the stress, thermodynamic model, relationship between polarization gradient and component gradient as well as the relationship between stress and dielectric-temperature stability [8]. Wang, Cheng and other persons from the Institute of Physics, CAS used the PLD method to study the gradient thick film $\left(\mathrm{Ba}_{0.8} \mathrm{Sr}_{0.2}\right)\left(\mathrm{Ti}_{1-\mathrm{x}} \mathrm{Zr}_{\mathrm{x}}\right) \mathrm{O}_{3}(\mathrm{x}=0.36,0.18$, $0.08,0)$ formed by $\mathrm{Zr}$ doping, and they also paid more attention to the dielectric properties of the multilayer comprised by these gradient layers [9].

The gradient thick film with $\mathrm{Ba}_{0.6} \mathrm{Sr}_{0.4-\mathrm{x}} \mathrm{MnxTiO}_{3}$ component is fabricated in the $\mathrm{Pt} / \mathrm{Ti} / \mathrm{SiO}_{2} / \mathrm{Si}$ silicon chip through rapid heat treatment by the sol-gel method, and the pyroelectric thick film with six doping layers of $\mathrm{Ba}_{0.6} \mathrm{Sr}_{0.4}$ ${ }_{x} \mathrm{Mn}_{\mathrm{x}} \mathrm{TiO}_{3} \quad(\mathrm{x}=0.02 、 0.03 、 0.04 、 0.05,0.06 、 0.07)$ is also fabricated in this paper, which can further improve the 
pyroelectric properties and wide the work temperature range of thick film.

\section{THEORY FOR GRADIENT FERROELECTRIC FILM}

To understand the characteristic of gradient ferroelectric film, the linear polarization gradient of ferroelectric film is assumed to be normal to the growing surface or silicon chip surface. Let $\mathrm{z}=0$ at the interface between silicon chip and thick film, then $\mathrm{P}(\mathrm{z})$ can be written as

$$
P(z)=D(z)-\varepsilon_{0} E(z)
$$

where $\varepsilon_{0}, \mathrm{D}$ and $\mathrm{E}$ are the vacuum dielectric constant, electric displacement and electric field, respectively. For the ferroelectric material, the electric displacement is

$$
D(z)=\varepsilon_{0} \varepsilon(z) E(z)+P_{s}(z)
$$

where $P_{s}$ and $\varepsilon(z)$ denote the spontaneous polarization and relative dielectric constant, respectively. For the gradient ferroelectric material, a series of double-well structure with two polarization states will occur. When $\mathrm{Z}$ decreases, each well will be offset to the low energy. For the gradient ferroelectric material without electrical field, if all the stresses are zero, the free energy $A(p)$ can be phenomenologically expressed as

$$
A(P)=K_{1} P^{2}+K_{2} P^{4}+K_{3} P^{6}
$$

where $\mathrm{k} 1, \mathrm{k} 2$ and $\mathrm{k} 3$ are only the function of temperature. The polarization strength of ferroelectric material is the function of temperature $\mathrm{T}$, strain $\delta$ and component c, etc. For small T, $\delta$ or c, $\nabla P \propto \nabla T, \nabla \delta$ or $\nabla c$ [16-18].

Slater [19] pointed out that the energy function of ferroelectric material can be written as

$$
\xi=K_{0}\left(T-T_{C}\right) x^{2}+B x^{4}
$$

where $\mathrm{x}, \mathrm{T}$, Tc denote the ionic displacement from center charge, temperature and Curie temperature of material, respectively. In addition, $\mathrm{k} 0$ and $\mathrm{B}$ are the function of temperature. When temperature decreases below the Curie temperature, the material becomes ferroelectric state.

For $T<T_{c}$, the energy maximums occur at the points of $x=0$ and $x= \pm \sqrt{K_{0}\left(T_{C}-T\right) / 2 B}$, the latter corresponding to the two spontaneous polarization values of ferroelectric dipole. Expending $\xi$ near

$$
x=\sqrt{K_{0}\left(T_{C}-T\right) / 2 B}
$$

and retaining only the quadratic term for

$$
x=\sqrt{K_{0}\left(T_{C}-T\right) / 2 B},
$$

then the following equation can be get

$$
\xi=\Delta \xi+\frac{1}{2}\left(x-\sqrt{K_{0}\left(T_{C}-T\right) / 2 B}\right)^{2} 4 K_{0}\left(T_{C}-T\right)
$$

$$
\Delta \xi=-\left[K_{0}\left(T_{C}-T\right)\right]^{2} / 4 B
$$

where $\Delta \xi$ is the relative depth of energy at

$$
x= \pm \sqrt{K_{0}\left(T_{C}-T\right) / 2 B}
$$

Ps is relative with energy function. Considering the Lorentz-Lorentz calibration of local depolarization field, $\Delta \xi$ is rewritten as

$$
\Delta \xi=-\frac{P_{S}^{2}}{24 N \varepsilon_{0}}
$$

where $\varepsilon_{0}$ is the dielectric constant of free space. The equation (6) provides an important outcome which uncovers the relationship between energy and spontaneous polarization. For ferroelectric material with much perovskite, the dielectric constant $\varepsilon$ and $P_{s}$ is approximately linear with component[20].

Here $\varepsilon=\left(\frac{\partial D}{\partial E}\right)_{E=0}$, where $\mathrm{D}$ and $\mathrm{E}$ are electrical displacement and electrical field, respectively. For linear component gradient normal to the growing surface,

$$
\begin{aligned}
& P_{S}=P_{S}\left(c_{0}\right)\left[1+\left(\frac{Z}{c_{0}}\right) \nabla c\right] \\
& \varepsilon=\varepsilon\left(c_{0}\right)\left[1+\left(\frac{Z}{c_{0}}\right) \nabla c\right]
\end{aligned}
$$

where $P_{S}\left(c_{0}\right)$ and $\varepsilon\left(c_{0}\right)$ are relative with temperature. The $C_{0}$ denotes the component of some reference plane along component gradient, and $\mathrm{Z}$ represents the vertical distance from reference plane to interface of thin film and silicon chip. Thus, the equation (6) can be transformed as

$$
\Delta \varepsilon=-\left[P\left(c_{0}\right)\right]^{2}\left[1+\left(\frac{Z}{c_{0}}\right) \nabla c\right]^{2} / 24 N \varepsilon_{0}
$$

The various thin films with multilayer structure can be fabricated with component gradient by the sol-gel technique. The thickness of thin film can be controlled by times of spin coating in different silicon chip. The ferroelectric thin film with component gradient, with suitable heat treatment, can be obtained by annealing.

\section{FABRICATION OF GRADIENT THICK FILM}

The Curie temperature of BST solid solution with continuous modulation from negative temperature (namely the transformation temperature of pure $\mathrm{SrTiO}_{3}$ ) to positive temperature (namely the Curie temperature of pure $\mathrm{BaTiO}_{3}$ ) can be obtained by the change of $(\mathrm{Ba} / \mathrm{Sr})$ ratio in the BST system, as can be seen in Fig.1.

To make the BST thick film work at the room temperature, the increasing temperature and decreasing temperature range of dielectric-temperature curve should be 
widen. The raw materials to fabricate $\mathrm{MnxBa}_{(0.6-\mathrm{x}) / 2} \mathrm{Sr}_{(0.4-}$ x) $/ 2 \mathrm{TiO}_{3}$ sol are mainly composed of $\mathrm{Ba}\left(\mathrm{C}_{2} \mathrm{H}_{3} \mathrm{O}_{2}\right) 2$ (briefly named $\left.\mathrm{Ba}(\mathrm{AC})_{2}\right)$, $\mathrm{Sr}(\mathrm{AC})_{2} \cdot 1 / 2 \mathrm{H}_{2} \mathrm{O}, \mathrm{Mn}(\mathrm{Ac})_{2}$ and $\mathrm{Ti}\left(\mathrm{OC}_{4} \mathrm{H}_{9}\right)_{4}$ (briefly named $\left.\mathrm{Ti}(\mathrm{OR})_{4}\right)$. The water, HAC and $\mathrm{C}_{2} \mathrm{H}_{5} \mathrm{O}\left(\mathrm{CH}_{2}\right)_{2} \mathrm{OH}$ are selected as solvent. The additives come from $\mathrm{C}_{3} \mathrm{H}_{7} \mathrm{NO}$ and $\left(\mathrm{CH}_{2} \mathrm{OH}\right)_{2}$, etc. After the hydrolysis, polycondensation and other reactions for the sol prepared by a given stoichiometry rate occur in air, the precursor solution of powder sol with certain $\mathrm{pH}$ value and viscosity can be formed, and then the ferroelectric thick film $\mathrm{Mn}_{\mathrm{x}} \mathrm{Ba}_{(0.6-}$ ${ }_{x) / 2} \mathrm{Sr}_{(0.4-\mathrm{x}) / 2} \mathrm{TiO}_{3}$ with $\mathrm{Mn}$ doping can be obtained by spin coating, baking, heat treatment and other techniques.

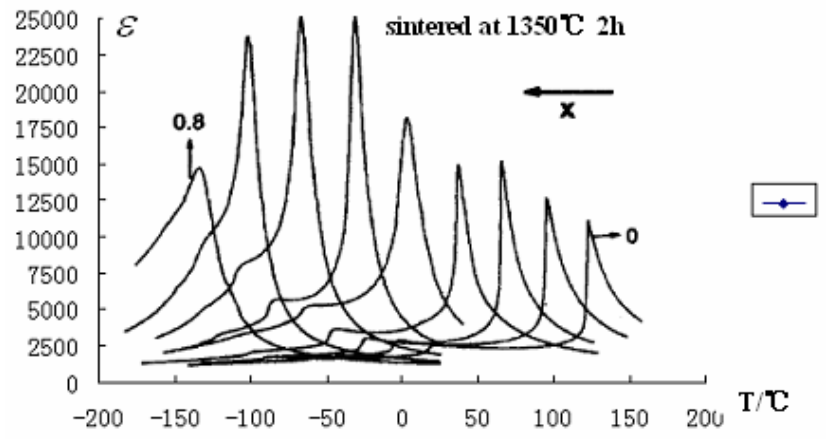

Fig. 1 Dielectric constant change of $\mathrm{Ba}_{1-\mathrm{x}} \mathrm{Sr}_{\mathrm{x}} \mathrm{TiO}_{3}$ ceramic sample with test temperature

The $\mathrm{Pt} / \mathrm{Ti} / \mathrm{SiO}_{2} / \mathrm{Si}$ structure can be obtained by thermal oxidation of single crystal silicon with silicon chip of orientation (100) and magnetron sputtering of bottom electrode. The reserving solution $\mathrm{Mn}_{\mathrm{x}} \mathrm{Ba}_{(0.6-\mathrm{x}) / 2} \mathrm{Sr}_{(0.4-\mathrm{x}) / 2} \mathrm{TiO}_{3}$ $(x=0.02 、 0.03 、 0.04 、 0.05 、 0.06 、 0.07)$ is dropped into the $\mathrm{Pt} / \mathrm{Ti} / \mathrm{SiO}_{2} / \mathrm{Si}$ silicon chip, and the desktop spin coater is used for coating with speed $3000 \mathrm{rpm}$ and operation time 30s. After coating, the BST thick films with approximately same thickness can be obtained by bakingthermal decomposition-annealing, repeated spin coating and heat treatment. Through six times of coating under the same conditions, the $\mathrm{MnxBa}_{(0.6-\mathrm{x}) / 2} \mathrm{Sr}_{(0.4-\mathrm{x}) / 2} \mathrm{TiO}_{3}$ multilayer with gradient BST thick film being about $5 \mu \mathrm{m}$ thickness and Mn gradient doping can be formed.The rapid heat treatment is applied for the annealing of gradient thick film, and then the pyrolyzed gradient thick film is put into the diffusion furnace at $750^{\circ} \mathrm{C}$ in 10 minutes. The furnace door is opened, and the film is taken back after decrease into the room temperature.

\section{RESULTS AND DISCUSSIONS}

Before you begin to format your paper, first write and save the content as a separate text file. Keep your text and graphic files separate until after the text has been formatted and styled. Do not use hard tabs, and limit use of hard returns to only one return at the end of a paragraph. Do not add any kind of pagination anywhere in the paper. Do not number text heads-the template will do that for you.

Mn-doping gradient BST thick film in $\mathrm{Pt} / \mathrm{Ti} / \mathrm{SiO}_{2} / \mathrm{Si}$ silicon chip can be seen that the initial crystallization temperature of gradient thick film $\mathrm{Mn}_{\mathrm{x}} \mathrm{Ba}_{(0.6-\mathrm{x}) / 2} \mathrm{Sr}_{(0.4-\mathrm{x}) / 2} \mathrm{TiO}_{3}$ is about $650^{\circ} \mathrm{C}$ with rapid heat treatment. far lower than that by traditional technique. However, this condition can not obtain good crystallization for BST gradient thick film. The strong crystallization peak with complete perovskite structure can be get under the condition of $750^{\circ} \mathrm{C}, 20 \mathrm{~min}$. The BST gradient thick film with complete crystallization conducts one-to-one correspondence with diffraction peak of ceramic powder, which shows that the BST gradient thick film generated in the $\mathrm{Pt} / \mathrm{Ti} / \mathrm{SiO}_{2} / \mathrm{Si}$ (100) silicon chip is polycrystalline film. Fig.2 shows the XRD spectrums of uniform Mn-doping samples in different concentrations. As the Mn doping increases, the maximum half width of the strongest diffraction peak is extended, and the (110) peak especially takes the most obvious displace, which shows the reduction of particle diameter and improvement of crystallization quality. The SEM analysis of BST ferroelectric thick film is conducted by Japanese SX-40 SEM. Fig. 3 shows the SEM picture of Mn-doping gradient thick film at the annealing temperatures of $650^{\circ} \mathrm{C}, 7500^{\circ} \mathrm{C}$ and 850 ${ }^{\circ} \mathrm{C}$, respectively. It can be seen from Fig.5 that the Mndoping gradient thick film at annealing temperature $750{ }^{\circ} \mathrm{C}$, $20 \mathrm{~min}$ takes on good crystallization. The grains are distributed uniformly with size range from $100 \mathrm{~nm}$ to $150 \mathrm{~nm}$ and average diameter $120 \mathrm{~nm}$. There are no fractures and voids in the thick film, and the grains are longer and larger than that by low temperature annealing.

Compared with BST materials by traditional solid phase synthesis, the gradient thick film of component $\mathrm{Mn}_{\mathrm{x}} \mathrm{Ba}_{(0.6-\mathrm{x}) / 2}$ $\mathrm{Sr}_{(0.4-\mathrm{x}) / 2} \mathrm{TiO}_{3}$, which is fabricated in the $\mathrm{Pt} / \mathrm{Ti} / \mathrm{SiO}_{2} / \mathrm{Si}$ silicon chip through rapid heat treatment by sol-gel method, can reduce the sintering temperature. The dielectric-temperature characteristic under $1 \mathrm{kHz}$ can be seen in Fig.4, with maximum dielectric constant near $25^{\circ} \mathrm{C}$, which means the transformation temperature moves into high temperature. Compared with BST with the same components, the BST thick film by sol-gel method performs obvious improvement of dielectric-temperature change rate under wide temperature range, wider transformation peak and tremendous reduction of dielectric loss, which can be used for the dielectric thermal UFPA and thus reduce tremendously the requirement for the signal processing circuit.

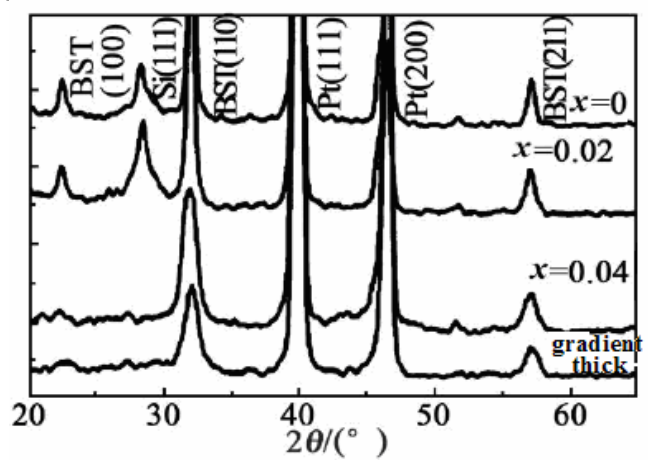

Fig.2 XRD spectrum of gradient thick film $\mathrm{Mn}_{\mathrm{x}} \mathrm{Ba}_{(1-\mathrm{x}) / 2} \mathrm{Sr}_{(1-\mathrm{x}) / 2} \mathrm{TiO}_{3}$ 


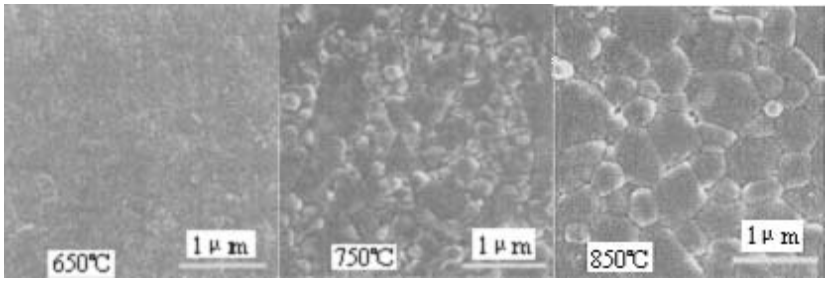

Fig.3 SEM picture of Mn-doping gradient thick film at different annealing temperatures

The dielectric materials with different component gradients may improve greatly the dielectric-temperature characteristic of gradient thick film due to lattice mismatch, because the atomic diffusion occurs between the adjacent layers. It is obvious that the measured value of dielectric constant of gradient multilayer has not been interpreted in terms of the series among monolayer films, so it is still a long way to go for this research. Compared with the BST thick film of single component, the $\mathrm{Mn}_{\mathrm{x}} \mathrm{Ba}_{(0.6-\mathrm{x}) / 2} \mathrm{Sr}_{(0.4-}$ x) $/ 2 \mathrm{TiO}_{3}$ ferroelectric thick film with variable component gradients performs excellent ferroelectric property and reinforced dielectric characteristic, basically because the previous deposited film later as the seed layer for the subsequent layer promotes the crystallization and growth of material. In addition, the diffusion among components can widen the pyroelectric FWHM, which testifies that the gradient multilayer method can promote the material properties.

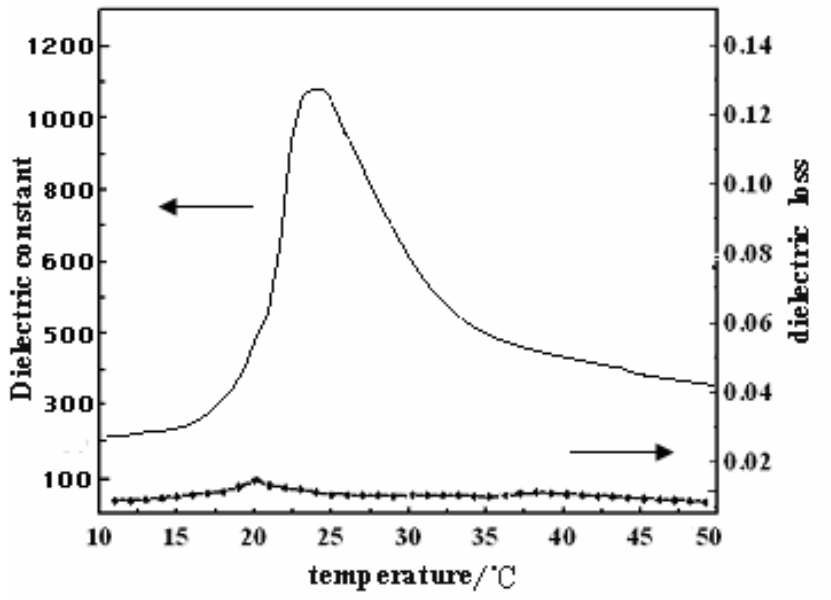

Fig.4 Dielectric-temperature characteristic of radient thick films

\section{CONCLUSIONS}

The Mn-doping BST gradient thick film, fabricated in the $\mathrm{Pt} / \mathrm{Ti} / \mathrm{SiO}_{2} / \mathrm{Si}$ silicon chip with improved sol-gel precursor by the spin coating method, can be processed into good uncooled infrared focal plane material at $750^{\circ} \mathrm{C}$. The tests show that ferroelectric material with gradient BST thick film has tremendous thermoelectric effect, with uniform surface grains and good density. In addition, the dielectric peak temperature zone of the gradient BST thick film covers the normal temperature with dielectric coefficient 1100 and dielectric loss approximately $1.8 \times 10^{-2}$. The reinforced thermoelectric effect of BST gradient thick film has been verified. However, there is still little theory about the BST gradient thick film, and more research should be carried on.

\section{REFERENCES}

[1] Cole M W,Joshi P C,Ervin M H.La doped $\mathrm{Ba}_{1-\mathrm{x}} \mathrm{Sr}_{\mathrm{x}} \mathrm{TiO}_{3}$ thin films for tunable device applications[J].J Appl Phys,2001,89(11) : $6336-$ 6340 .

[2] Chong $\mathrm{K} \mathrm{B}$,Kong $\mathrm{L} \mathrm{B}$, Chen $\mathrm{L}$ F,et al.Improvement of dielectric loss tangent of $\mathrm{Al}_{2} \mathrm{O}_{3}$ doped $\mathrm{Ba}_{0.5} \mathrm{Sr}_{0.5} \mathrm{TiO}_{3}$ thin films for tunable microwave devices[J].J Appl Phys,2004,95(3) : 1416-1419.

[3] Ahn K H,Baik S,Kim S S.Significant suppression of leakage current in $(\mathrm{Ba}, \mathrm{Sr}) \mathrm{TiO}_{3}$ thin films by $\mathrm{Ni}$ or $\mathrm{Mn}$ doping[J].J Appl Phys,2002,92(5) : 2651-2654.

[4] Adikary S U,Chan $\mathrm{H} \mathrm{L}$ W.Compositionally graded $\mathrm{Ba}_{\mathrm{x}} \mathrm{Sr}_{1-\mathrm{x}} \mathrm{TiO}_{3}$ thin films for tunable microwave applications[J].Mater Chem Phys,2003,79: 157-160.

[5] Tian H Y,Chan H L W,Choy C L,et al.The effects of composition gradients of $\mathrm{Ba}_{\mathrm{x}} \mathrm{Sr}_{1-\mathrm{x}} \mathrm{TiO}_{3}$ thin films on their microstructures,dielectric and optical properties[J].Mater Sci Eng B,2003,103 : 246-252.

[6] Zhai J W,Chen H.Nonlinear behaviors of the compositionally graded $(\mathrm{Ba}, \mathrm{Sr}) \mathrm{TiO}_{3}$ thin films derived by a sol-gel process[J].Appl Phys Lett, 2004,84(7) : 1162-1164.

[7] Cao H X,Gao Y H,Jiang Q,et al.Thermodynamic properties of compositionally graded $\mathrm{Ba}_{1-\mathrm{x}} \mathrm{SrxTiO}_{3}$ thin films[J].J Appl Phys,2004,96 (3) : 1628-1634.

[8] Lee S J,Moon S E,Ryu $\mathrm{H}$ C,et al.Microwave properties of compositionally graded( $\mathrm{Ba}, \mathrm{Sr}) \mathrm{TiO}_{3}$ thin films according to the direction of the composition gradient for tunable microwave applications[J].Appl Phys Lett,2003,82(13) : 2133-2135.

[9] Wang C,Cheng B L,Wang S Y,et al.Improved dielectric properties and tunability of multilayered thin films of $\left(\mathrm{Ba}_{0.80} \mathrm{Sr}_{0.20}\right)\left(\mathrm{Ti}_{1-\mathrm{x}} \mathrm{Zrx}\right) \mathrm{O}_{3}$ with compositionally graded layer[J].Appl Phys Lett,2004,84(5) : $765-767$.

\section{Author}

Fan Maoyan was born in Yunnan Province, China, in 1968. He received the M.S. degree from the Department of Solid State Electronics, Huazhong University of Science and Technology (HUST), Wuhan, in 1996 and the Ph.D. degree from the Department of Electronic Science and Technology, HUST, Wuhan, in 2009. he had done postdoctoral research In 2012, He is currently a Senior Engineer with YXNU. His research interests include information materials and micro-sensor technique. 